Check for updates

Montreal

Cite this as: $B M J 2020 ; 371: \mathrm{m} 4338$ http://dx.doi.org/10.1136/bmj.m4338 Published: 09 November 2020

\section{Covid-19: Denmark to kill 17 million minks over mutation that could undermine vaccine effort}

\author{
Owen Dyer
}

Scientists at the World Health Organization and around the world are studying a mutated variant of the novel coronavirus that is infecting humans after spreading through mink farms in the north of Denmark.

One strain of mutated SARS-CoV-2, found in 12 humans in Denmark, appeared in laboratory tests to exhibit "decreased susceptibility" to antibodies from previously infected people, the country's State Serum Institute said in a preliminary report. ${ }^{1}$ This variant, if it spread, might be less easily controlled by covid-19 vaccines currently under development, the report warned.

The only safe option, said Danish prime minister Mette Frederiksen, is to cull all 17 million minks kept by the Danish fur industry. Denmark is the world's biggest mink fur exporter, supplying about a third of global demand.

"We have a great responsibility towards our own population, but with the mutation that has now been found we have an even greater responsibility for the rest of the world," Frederiksen told a press conference on 6 November.

"The mutated virus in minks could pose a risk that future vaccines won't work as they should. It risks being spread from Denmark to other countries. The eyes of the world are on us.”

Frederiksen announced local lockdowns in seven districts of North Jutland, where the fur industry is concentrated. Mink farmers took to the roads in tractors to protest as public health teams began a cull that is expected to last two weeks. Germany and the UK added Denmark to their quarantine lists in response.

Like many mammals, minks are susceptible to infection by the novel coronavirus, and it spread rapidly through Denmark's densely caged mink farm populations this summer. Similar outbreaks have already triggered smaller culls at mink farms in Spain, the Netherlands, and the US.

Five different virus strains have since been detected in Danish patients that first passed through the farmed mink population and underwent changes in the process. The mutations involve changes to the spike protein that the virus uses to penetrate human cells. This protein is also the main focus of vaccine efforts.

Among 5102 samples of virus taken from Danish patients since June, five infection clusters affecting 214 people involved mink variant virus. One of these, known as cluster 5 , is the problematic variant believed less susceptible to antibodies. This cluster affected 11 people in North Jutland and one on the island of Zealand. In North Jutland nearly half of recent human covid-19 cases involved a mink variant, while elsewhere in Denmark the proportion is under $1 \%$.

The mink variant viruses show no sign of spreading faster or causing more severe symptoms than other strains of SARS-CoV-2, and many experts have expressed scepticism over Danish government claims that these mutations could seriously undermine uploading genetic sequences onto public databases for other scientists to study.

The cluster 5 variant has "moderately decreased statement acknowledged. ${ }^{2}$ "[It] had a combination of mutations, or changes that have not been previously observed. The implications of the identified changes in this variant are not yet well understood."

This was a “concern," said Maria van Kerkhove, WHO's technical lead on covid-19. But "mutations are normal," she added. "I don't think we should come to any conclusions about whether this particular mutation is going to impact vaccine efficacy."

"We need to wait and see what the implications are," said WHO chief scientist Soumya Swaminathan.

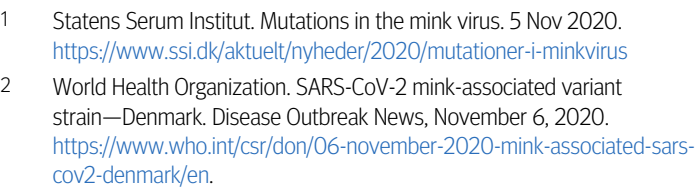

This article is made freely available for use in accordance with BMJ's website terms and conditions for the duration of the covid-19 pandemic or until otherwise determined by BMJ. You may use, download and print the article for any lawful, non-commercial purpose (including text and data mining) provided that all copyright notices and trade marks are retained. vaccine efforts. Danish authorities have begun sensitivity to neutralising antibodies," a WHO 